Disponível em

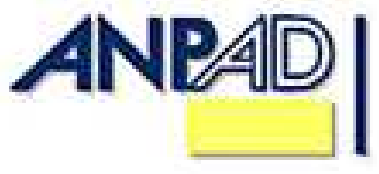

http://www.anpad.org.br/rac

RAC, Rio de Janeiro, v. 16, n. 6, art. 3, pp. 806-826, Nov./Dez. 2012

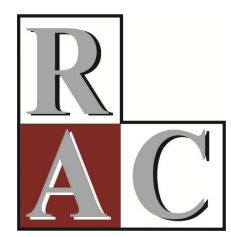

(oc) EY-NC

\title{
Comunidades de Prática enquanto Viabilizadoras de Projetos Comuns em Ambientes Turbulentos: uma Abordagem Crítica
}

Communities of Practice as Facilitators of Collaborative Efforts in Turbulent Environments: a Critical Approach

Patricia Gazzoli *

E-mail: patricia.gazzoli@gmail.com Université du Québec à Montréal - UQAM

Québec, Canadá. 


\title{
Resumo
}

Em ambientes cada vez mais turbulentos e competitivos, as empresas privadas são paradoxalmente impelidas a funcionarem em colaboração pontual ou a longo prazo. A fim de compreender como tais processos de colaboração podem ser viabilizados, o presente artigo analisa a experiência de uma comunidade de prática no Canadá, formada com o intuito de promover a melhoria de qualidade dos serviços públicos. Esta comunidade de prática contou com a participação dos governos provinciais e federal, conquanto, reconhecidamente, as relações federais no Canadá são de rivalidade e tensão. Uma análise baseada nas teorias críticas esclarece como a comunidade de prática tornou possíveis iniciativas comuns, como a realização de sondagens pancanadenses de satisfação de serviços. A partir do paralelo que pode ser estabelecido entre a situação estudada e os ambientes competitivos nos quais as empresas privadas se localizam, o artigo argumenta que o setor público pode inspirar as práticas privadas no sentido de utilizarem-se de comunidades de prática como estratégia para esvaziar o conteúdo ideológico de iniciativas e viabilizar esforços colaborativos.

Palavras-chave: comunidades de prática; colaboração; ambientes competitivos; estratégia; serviços públicos.

\begin{abstract}
Facing more turbulent and competitive environments, private companies are paradoxically forced to collaborate, over short or long-term periods. In order to better understand how these collaboration processes take place, this article analyses the experience of a community of practice in Canada, established in order to promote quality improvement of public services. This community of practice counted upon the participation of provincial and federal governments, even though federal-provincial relations in Canada are characterized by tension and rivalry. From a critical and qualitative perspective, our analysis shows how the community of practice promoted cooperation in common projects, such as the adoption of a pan-Canadian survey on satisfaction with public services. As we can establish a parallel between the Canadian federal environment and the competitive environments of private companies, we believe that the public sector can inspire private practices, in the sense of using communities of practice as a strategy to diminish the ideological component of initiatives and make collaborative efforts possible.
\end{abstract}

Key words: communities of practice; cooperation; competitive environments; strategy; public services. 


\section{Introdução}

Embora situadas em um ambiente cada vez mais competitivo e turbulento, as empresas, hoje, veem-se, de mais a mais, constrangidas a colaborarem, operando em joint ventures, consórcios, alianças ou outros tipos de parcerias pontuais ou a longo prazo. Tais parcerias promovem a aprendizagem interorganizacional, aumentam a competitividade das empresas ou diminuem os riscos de competição aos quais elas estão expostas (Espinosa \& Suanes, 2011; Klijn, Reuer, Buckley, \& Glaister, 2010; Tong \& Reuer, 2010; Yen-Tsung, 2010). Conquanto competitividade e colaboração soem paradoxais, a complexidade dos projetos, a demanda por produtos e serviços articulados e a impossibilidade econômica e administrativa de concentração vertical impõem a cooperação entre empresas, justamente para fazer face a este ambiente de extrema rivalidade.

No entanto, tal cooperação não se desenvolve sem problemas. Passar de rivais a cooperadoras em projetos comuns implica em uma mudança de mentalidade e comportamento importante e essencial ao sucesso da empreitada comum. Tal mudança não deve se operar somente nos altos escalões estratégicos das empresas, mas precisa acontecer efetivamente no âmbito operacional, entre os empregados designados para a participação no projeto comum. Impelidos a identificarem-se com sua empresa, incorporando seus valores, sua história e seus objetivos, impõe-se a eles, ao mesmo tempo, ignorarem uma história e uma situação mercadológica caracterizadas pela concorrência tecnológica, operacional e estratégica a fim de privilegiar a colaboração com aqueles que, anteriormente, eram seus rivais ou mesmo continuam sendo, ainda que em outras esferas da empresa.

Neste contexto, uma situação estudada na administração pública pode inspirar as empresas privadas. Trata-se da experiência de uma comunidade de prática, compreendendo gestores dos governos federal e provinciais canadense. Tal comunidade foi criada a fim de viabilizar a realização de uma sondagem de satisfação de serviços em nível nacional, com a participação de todas as províncias e principais cidades do país, além do governo federal. Ora, historicamente, o federalismo canadense é reconhecido como politicamente turbulento, destacando-se a ideologia separatista da província do Quebec, de colonização e língua francesa, diferentemente do restante do Canadá. Nos anos de 1990, movimentos separatistas também surgiram no oeste canadense, sobretudo em Alberta, movimentos atribuídos principalmente à descoberta do petróleo na província e a reivindicações não contempladas pelas políticas federais. No entanto, mesmo em tal ambiente, em que as províncias contendem com o governo federal não só política, mas, também, economicamente, foi possível a realização de um projeto comum que dura desde 1998, as sondagens de satisfação em nível nacional.

O objetivo deste artigo é analisar como tal iniciativa comum foi viabilizada em um ambiente altamente turbulento, através da constituição de uma comunidade de prática, formada por gestores públicos de diferentes esferas de governo. Para isso, recorremos às teorias críticas que revelam o componente ideológico da comunidade de prática e ajudam a compreender como o projeto comum tornou-se possível.

Embora muito tenha sido escrito sobre comunidades de prática existentes tanto no setor privado quanto público, tais estudos abordam, sobretudo, os processos e os resultados de aprendizagem que se realizam nesses grupos, cujos participantes se identificam a partir de sua prática no mundo do trabalho (Brandon \& Charlton, 2011; Habhab-Rave, 2010; Vickers \& Fox, 2010). Outras pesquisas, como a de Souza-Silva (2009), tentam discernir condições específicas que levam à formação ou favorecem o desenvolvimento de comunidades de prática.

Poucos estudos foram realizados no que concerne às comunidades de prática sob uma perspectiva crítica, e aqueles que o fizeram abordaram, sobretudo, as dificuldades que diferentes indivíduos experimentam para construir relações significativas que promovem a aprendizagem. Segundo os autores, tais dificuldades surgem porque as comunidades reproduzem relações de poder entre indivíduos que apresentam diferentes capitais (econômicos, sociais ou políticos) (Heizmann, 2011; Hong \& O, 2009; Hughes, Jewson, \& Unwin, 2007; Mutch, 2003). Concentrando-se no ambiente micro, tais pesquisas apontam que diferenças entre o status socioprofissional impossibilitam 
a colaboração e a construção de relações de confiança nas comunidades de prática, dificultando a aprendizagem (Simpson, 2011).

Todavia o componente ideológico das comunidades de prática e sua utilização estratégica pelos membros participantes não se apresenta como uma preocupação prioritária para os autores que se dedicam ao tema. Nesse contexto, o presente artigo responde a esta lacuna analítica, propondo-se a abordar as comunidades de prática segundo teorias críticas as quais reafirmam que toda prática de gestão é também orientada e utilizada ideologicamente (Alvesson, Bridgman, \& Willmott, 2009; Alvesson \& Deetz, 2000; Alvesson \& Willmott, 1996; Kirkpatrick \& Martinez-Lucio, 1995; Rouleau, 2007; Scherer, 2009). Somente através dessa perspectiva é possível compreender como e por que a comunidade de prática foi constituída e como se desenvolveu em um ambiente conflituoso. $\mathrm{O}$ argumento apresentado, neste texto, é no sentido de que a própria racionalidade instrumental que rege as comunidades de prática, orientada para o aprendizado de indivíduos que realizam atividades comuns em várias organizações, ajudou a encobrir o caráter político do projeto de sondagens. Mais ainda, desta forma, o projeto foi afastado das esferas de decisão política através das quais seria provavelmente impossível realizar sondagens de satisfação em relação aos serviços públicos oferecidos pelos três níveis de governo canadense (federal, provincial e municipal).

A situação aqui apresentada foi abordada em tese de doutorado, na qual foram estudadas as diferentes estratégias de implantação das sondagens de satisfação em relação aos serviços públicos no Canadá e nos Estados Unidos (Gazzoli, 2004a). Neste texto, a partir de teorias críticas, será abordada apenas a estratégia canadense, que se caracteriza pela formação da referida comunidade de prática. Para tanto, uma metodologia qualitativa foi empregada no estudo. Os dados, coletados nas entrevistas realizadas junto aos responsáveis pelas sondagens de satisfação no Canadá e em documentos institucionais do governo, foram submetidos a análises de conteúdo e de discurso.

Além desta introdução, o presente texto se apresenta em mais cinco partes. Primeiramente, é introduzido o quadro teórico adotado, que compreende a teoria das comunidades de prática e as teorias críticas. Em segundo lugar, é apresentada a metodologia de pesquisa. Na continuidade, detalha-se o contexto em que foi adotada a sondagem de satisfação, o qual foi marcado por relações federais conflituosas. Caracteriza-se, em seguida, a formação da comunidade de prática em questão. No quarto momento, discute-se, criticamente, o fenômeno de formação das comunidades de prática que, embora tenha esvaziado a sondagem de satisfação de seu conteúdo político, possibilitou sua realização. Finalmente, é salientada a contribuição deste estudo para o setor privado, que enfrenta igualmente ambientes turbulentos, tanto econômica quanto politicamente.

\section{Quadro Teórico de Pesquisa: Comunidades de Prática e Teorias Críticas}

\section{As comunidades de prática}

Foi Etienne Wenger $(1999,2000)$ quem utilizou, pela primeira vez, a expressão comunidades de prática (communities of practice) nos estudos administrativos. As comunidades de prática são consideradas como espaços de aprendizagem por excelência ${ }^{(1)}$, grupos em grande demanda em organizações sujeitas a um ritmo acentuado de mudanças e que devem garantir um fluxo contínuo de informações para permanecerem em dia com as inovações técnicas e gerenciais. É o caso das grandes empresas divididas em filiais ${ }^{(2)}$, das multinacionais ${ }^{(3)}$ e dos setores de ponta. Nesse aspecto, as administrações públicas são também excelentes candidatas à utilização de comunidades de prática pelo seu porte e dispersão geográfica. A recente introdução de novas práticas gerenciais que apresentam, como efeito secundário, a fragmentação administrativa, também, justifica a formação de comunidades de prática no setor público (Meagher-Stewart et al., 2012; Snyder, Wenger, \& Briggs, 2004).

Segundo a teoria, as comunidades de prática são redes formadas por indivíduos que possuem conhecimento ou interesse numa determinada área, sendo que, na maioria das vezes, essa área está 
relacionada ao seu trabalho (Wenger, 2000). Tais indivíduos se reúnem para discutir suas abordagens e práticas de trabalho, de forma a desenvolver seus conhecimentos em uma área pouco explorada empiricamente ou pela literatura sobre gestão, ou seja, onde o conhecimento formal é escasso. Wenger (2000) define as comunidades de prática como sendo espaços de aprendizagem social, um fenômeno produzido quando existe uma dissonância entre a competência social (situada social e historicamente) e a experiência dos participantes.

Nonaka e Takeuchi (1995) explicam o porquê de recorrer às comunidades de prática como sistemas de aprendizagem. Segundo esses autores, podemos distinguir dois tipos de conhecimento: o tácito e o explícito. O conhecimento explícito é codificado e pode ser comunicado por meio de uma linguagem formal. Assim, a sua difusão é facilitada. Com relação ao conhecimento tácito, no entanto, é diferente. Os indivíduos não estão necessariamente capacitados para comunicar o que sabem. Segundo Polanyi (1996 como citado em Raelin, 1998, p. 280, tradução nossa): "O conhecimento tácito é o componente do conhecimento que não é tipicamente transferível, uma vez que está profundamente ancorado na ação e no envolvimento em um contexto específico". Persaud, Kumar e Kumar (2001, p. 13, tradução nossa) reforçam: "O conhecimento tácito não pode ser facilmente codificado e transferido. Ele também não é de acesso fácil. É o conhecimento que as pessoas carregam em suas cabeças, é intuitivo e baseado na experiência".

Segundo Persaud et al. (2001), o contato pessoal no âmbito das comunidades de prática é essencial para a transmissão de conhecimento tácito. $\mathrm{O}$ fato de as trocas de ideias se basearem em experiências de trabalho concretas facilita a expressão do ponto de vista dos indivíduos. A informalidade no âmbito da comunidade de prática e a participação voluntária dos membros estimulam igualmente a sinergia entre os indivíduos e, consequentemente, a aprendizagem. Além disso, os mecanismos de funcionamento elaborados pelas comunidades de prática estruturam o conhecimento do grupo.

Lesser e Storck (2001, p. 831, tradução nossa) elaboram no mesmo sentido, segundo os autores, deve-se entender por comunidade de prática "um instrumento de desenvolvimento de capital social", que visa não apenas ao intercâmbio de conhecimentos, mas também à mudança dos comportamentos. Os autores adotam a definição de Nahapiet e Ghoshal, para quem, o capital social é "a soma dos recursos contidos na rede de relações de um indivíduo ou de uma unidade social, recursos que estão disponíveis na rede e derivam dela" (Lesser \& Storck, 2001, p. 833, tradução nossa). Lesser e Storck (2001) acreditam que são três as dimensões que definem o capital social: os indivíduos devem sentir que fazem parte de uma rede (dimensão estrutural); um sentimento de confiança e de compartilhamento deve se desenvolver entre os participantes do grupo (dimensão relacional); os indivíduos compartilham interesses comuns e têm uma compreensão comum dos problemas que enfrentam (dimensão cognitiva).

Como se assinalará adiante, o grupo responsável pela sondagem de satisfação canadense caracteriza-se como sendo uma comunidade de prática. Nossa análise aponta que tal comunidade de prática tornou possível a união de membros de vários governos para a realização do projeto de sondagem em nível nacional, mesmo em um contexto cuja colaboração entre as províncias e o governo federal é, historicamente, turbulenta.

\section{As teorias críticas}

Teorias críticas (Alvesson et al., 2009; Alvesson \& Deetz, 2000; Alvesson \& Willmott, 1996; Kirkpatrick \& Martinez-Lucio, 1995; Rouillard, 1999; Rouleau, 2007; Scherer, 2009) orientaram a análise aqui apresentada, sobre a constituição de comunidades de prática enquanto estratégia (embora não sempre conscientemente empregada por todos os atores) que possibilitou a colaboração em um ambiente politicamente turbulento. As teorias críticas ressaltam a importância dos atores e seus valores, interesses, interpretações e escolhas. Como se verá, a seguir, a interpretação dos atores governamentais sobre o significado da comunidade de prática criada foi fundamental para a realização conjunta de uma sondagem de satisfação nacional. 
As teorias críticas contribuíram principalmente de duas maneiras. A primeira delas reside no fato de que tais teorias privilegiam a contextualização empírica como a única forma de se apreender o significado de um determinado fenômeno. Assim, o discurso administrativo só tem sentido se contextualizado, quando podemos, então, apreendê-lo como um construto ideológico (Alvesson \& Willmott, 1996). A própria noção de eficiência, fora de contexto, torna-se incompleta e sem sentido. Quando nos referimos à eficiência do governo, a qual eficiência nos referimos? À eficiência política, social, institucional ou técnica? Eficiência a curto, médio ou longo prazo? Eficiência para um setor específico do governo ou para a máquina pública em geral?

Contrariamente à ideia defendida pelas correntes tradicionais da administração, nas teorias críticas, a eficiência assume um papel polissêmico (Rouillard, 1999). Ao invés de corresponder aos cálculos de relação entre custos e benefícios, ou seja, meios e fins, sendo considerado um conceito neutro e incontestável, a eficiência assume significados diferentes. Ela não se limita, portanto, ao seu aspecto técnico, até então defendido como o objetivo primordial de toda organização. Isso porque fins são estabelecidos por grupos que apresentam posturas ideológicas e interesses próprios. Fins diferentes definem eficiências ideologicamente diversas. Portanto a eficiência deve ser vista como um construto ideológico, ainda que ele tenha sido naturalizado pelo discurso mercantilista: a eficiência técnica, privilegiada pela empresa privada, é somente a eficiência que corresponde aos interesses capitalistas (Alvesson et al., 2009; Alvesson \& Willmott, 1996; Scherer, 2009).

As teorias críticas contribuíram para a análise aqui apresentada também de uma segunda maneira. As abordagens de gestão se desenvolvem, em sua grande maioria, em torno da ideia da racionalidade instrumental e, mais tarde, em torno da ideia de racionalidade limitada apresentada por Simon (1947). Os autores críticos requestionam noções tidas como naturais na ordem organizacional contemporânea. A ampliação da noção de racionalidade é uma contribuição fundamental da abordagem crítica. Segundo Rouillard (1999), além da racionalidade instrumental ou cognitiva, há pelo menos duas outras dimensões da realidade que devem ser consideradas: uma dimensão substantiva ou valorativa e outra afetiva ou emocional. As diferentes dimensões da racionalidade são vividas ao mesmo tempo pelos atores, e diferentes racionalidades se cruzam na interação humana. As realidades organizacionais são, dessa maneira, construídas e reconstruídas, interpretadas e reinterpretadas pelos atores organizacionais, o que garante tanto a mudança quanto a continuidade organizacional.

Ampliando o conceito de racionalidade, as teorias críticas proporcionam também a reconsideração dos processos decisórios e da articulação de grupos internos, partindo de pontos de vista que envolvem interesses, valores e afetividades dos atores envolvidos. Pode-se, assim, situar uma ação ideologicamente ou criticá-la dentro de um determinado contexto, interpretado não só pelos atores em questão, mas também pelo pesquisador. Veremos, na análise subsequente, que a superposição de uma lógica instrumental à lógica política dos governos possibilitou a realização da sondagem de satisfação envolvendo todas as províncias e o governo federal do Canadá.

\section{Quadro Metodológico de Pesquisa}

Epistemologicamente, este trabalho se baseia em uma perspectiva construcionista e crítica, segundo a qual, a realidade é construída a partir das percepções dos atores e da interpretação que o pesquisador faz dos fenômenos observados. Assim, os elementos são abordados a partir da maneira como são percebidos pelos atores organizacionais e, posteriormente, pelos pesquisadores, durante a realização do estudo. Os resultados desta pesquisa são, portanto, frutos da interação pesquisadorespesquisados, de suas respectivas lógicas, de seus valores e preferências. Em momento algum, as opiniões ou interpretações críticas dos autores devem ser camufladas, pois elas não constituem um desvio de rigor, segundo o paradigma crítico (Guba, \& Lincoln, 1994; Holstein \& Gubrium, 2011; Packer, 2011; Silverman \& Marvasti, 2008). 
Adotando uma metodologia qualitativa, o primeiro passo foi realizar uma análise documental exaustiva sobre as iniciativas de modernização da administração federal canadense, ocorridas entre 1989 e 2003 . Nossa atenção se concentrou particularmente na análise dos documentos públicos que se referiam à sondagem de satisfação sobre os serviços canadenses. Esta sondagem é realizada, desde 1998, pelo governo federal e províncias, em parceria com o Institut des services axés sur le citoyen, instituição criada pelo grupo de responsáveis quanto à sondagem federal para a administração periódica da sondagem.

Os documentos se referiam tanto a mudanças de gestão inspiradas na filosofia da qualidade de serviços quanto a detalhes técnicos da sondagem de satisfação. Desde o primeiro momento, o grupo de participantes da sondagem federal chamou a atenção para incluir todas as províncias (e mesmo alguns grandes municípios) canadenses, além do governo federal. Particularmente, o governo do Québec fazia parte da iniciativa, embora prevalecesse, na época, um clima de grande hostilidade ao governo federal. Tal hostilidade se devia, em parte, à derrota no referendum de 1995, sofrida por aqueles que defendiam a soberania do Québec e, em parte, às posteriores iniciativas federais que favoreciam a divulgação intensiva da presença federal na província do Québec.

Após a pesquisa documental, foram realizadas entrevistas semiestruturadas com doze gestores e altos funcionários responsáveis pelas sondagens de satisfação no Canadá, inclusive com aqueles que estiveram intimamente envolvidos na implantação das sondagens, mas que já tinham deixado o projeto. As entrevistas individuais tiveram uma duração de 60 a 90 minutos e todos os informanteschave (identificados pelo grupo em um processo bola de neve) consentiram em ser entrevistados. A amostragem (não aleatória) incluiu também um membro do Institut des services axés sur le citoyen e um membro do instituto de pesquisa de opinião que havia operacionalizado a sondagem. Foram entrevistados dois representantes do governo federal e oito outros representantes das 10 províncias canadenses. Tais indivíduos foram considerados, por seus pares, como altamente implicados no projeto de sondagens. A maioria das entrevistas foi realizada pessoalmente, mas três delas foram efetuadas por telefone, devido à localização geográfica dos entrevistados.

As entrevistas buscaram retraçar o processo de concepção da sondagem, que logo se revelou estar intimamente ligado à formação da comunidade de prática responsável pela sondagem (Réseau des services axés sur le citoyen [RSAC]). Nas entrevistas, incitou-se a expressão livre dos entrevistados sobre sua experiência no grupo e, em momento algum, foi sugerido pelo pesquisador que se tratava ali de uma comunidade de prática. No caso das entrevistas com os representantes do governo federal e do Québec, questões específicas foram introduzidas sobre o contexto político federal e seu impacto sobre a participação da província na realização da sondagem federal.

As entrevistas foram transcritas verbatim e submetidas a uma análise de conteúdo (Sabourin, 2009). Dois entrevistados pediram que suas entrevistas não fossem gravadas. Nestes casos, notas tomadas durante e após a entrevista constituíram o material da análise efetuada com o programa AtlasTI, mas tal conteúdo não foi considerado em citações. Entre os vários temas identificados na análise de conteúdo, a percepção dos atores sobre a formação da comunidade de prática e sobre a realização da sondagem serviu de substrato importante para a análise crítica aqui apresentada. A análise do discurso (Mazière, 2010; Peräkyla \& Ruusuvuori, 2011) dos documentos relativos à reforma administrativa canadense, em particular, daqueles que dizem respeito à filosofia de melhoria da qualidade dos serviços, também, forneceu dados importantes para a pesquisa. Além disso, informações históricas sobre o governo federal canadense contribuíram para o desenvolvimento da análise. Observa-se que, devido ao número de entrevistados e à intensidade de suas relações, suas falas não foram identificadas, mesmo por números, em publicações da pesquisa. Buscou-se assim assegurar o anonimato dos respondentes. Todos os nomes próprios também foram omitidos das citações e substituídos por traços contínuos. 


\section{A Formação da Comunidade de Prática: Contexto e Processo}

\section{As relações intergovernamentais canadenses}

No Canadá, as relações entre as províncias e o governo federal sempre apresentaram alguma tensão (Broschek, 2010; Pelletier, 2008). Alain-G. Gagnon $(2001,2008)$ atribui as diferenças à existência de mais de uma nacionalidade no estado federal canadense, o que resulta na constituição de um federalismo multinacional, o que é também o caso da Espanha e da Bélgica. Historicamente, a federação canadense foi constituída graças à associação entre dois povos (francófonos e anglófonos ${ }^{(4)}$ ) e a existência de um povo particular no território do Baixo Canadá (Quebec) é reconhecida no seu ato de fundação (Acte de l'Amérique du Nord Britannique) (Ryerson, 1978 como citado em Noël, 1998).

Segundo Gagnon (2001), o federalismo multinacional remete em questão os princípios do Estado liberal e das sociedades federais democráticas, marcadas pela homogeneidade, onde encontrase uma só comunidade política, que comunga uma visão do mundo, fala a mesma língua, tem os mesmos ancestrais e apresenta uma cultura identificável. Ao invés de se fundar sobre os princípios do individualismo, da igualdade e do universalismo, próprios dos Estados federais homogêneos, Gagnon (2001, 2008) sugere que, nos federalismos multinacionais, deve-se levar em consideração os princípios das comunidades políticas e culturais, da equidade e da democracia estendida. Trata-se, em outras palavras, de proteger a existência das várias comunidades nacionais e de permitir a todos os indivíduos o acesso às mesmas oportunidades, oferecendo-lhes um tratamento regido pela equidade. Significa igualmente promover o diálogo democrático entre as comunidades políticas da federação. $\mathrm{O}$ autor clama, assim, por um federalismo assimétrico (Gagnon, 2008).

A tensão entre as comunidades políticas que defendem um Estado federal homogêneo e aquelas que defendem um Estado assimétrico caracteriza as relações federais-provinciais no Canadá (Gagnon, 2008, Pelletier, 2008). A formulação de políticas públicas se caracteriza por disputas jurisdicionais importantes, marcadas pela negociação e pela consulta das províncias, o que limita o poder federal. As ações do governo federal são mesmo consideradas coercitivas, pois as prioridades federais podem não corresponder às prioridades provinciais (Radin \& Boase, 2000).

Em alguns momentos, o sistema federal canadense chegou efetivamente a ser questionado. Sobretudo, após 1960, as relações intergovernamentais caracterizaram-se como uma questão política, ao invés de um problema meramente burocrático. Segundo Kerneghan (1982), entre 1960 e 1985, instala-se, no Canadá, um federalismo competitivo, com a demanda de maior autonomia pelas províncias. No Quebec, a Revolução Tranquila, responsável pela instituição do estado do bem-estar e pela ascensão do Partido Québécois ao poder, defendeu a maioria francófona contra o julgo anglófono. Nesta época, o debate entre representantes políticos atinge seu auge, nas figuras de René Lévesque do Partido Québécois, de aspiração separatista, e Pierre Eliot Trudeau, de orientação centralizadora e federalista. Na mesma época, também, em Alberta, surgiu o debate contra a centralização federal, quando o político Peter Lougheed questionou o Plano de Energia Nacional. Também, por mais de uma vez, levantes dos povos autóctones desafiaram sua submissão ao governo canadense.

Em 1980, foi realizado um primeiro referendo no Quebec consultando a população sobre uma possível separação do resto do Canadá. Embora trouxesse resultados negativos para os separatistas, o referendo promoveu o debate sobre o separatismo em todas as esferas da sociedade. Em 1982, o Quebec entrou em conflito aberto com o governo federal, recusando-se a assinar a repatriação da Constituição canadense, então sob controle da Rainha da Inglaterra, que mantinha um poder formal (embora não efetivo) sobre as questões constitucionais da antiga província. Tal postura do governo quebequense se justificou pela recusa do governo federal em admitir o direito de veto das províncias em relação às emendas constitucionais.

Em 1987, no Sommet du Lac Meech, encontro de primeiros-ministros canadenses, as províncias canadenses recusaram-se a reconhecer o caráter distinto do Quebec, o que só foi conseguido em 1992, 
na reunião dos primeiros-ministros em Charlottetown. Admitiu-se, então, que a sociedade quebequense era distinta, ou seja, uma sociedade de maioria francófona, com cultura particular e seguidora do Direito Civil. Na crítica de Rocher, Rouillard e Lecours (2001), tal reconhecimento não beneficiou a autonomia do Quebec. Segundo os autores, o caráter distinto da sociedade quebequense (reafirmado em 1997 em Calgary) foi definido de forma fluida e ambígua, sem que houvesse um reconhecimento formal do federalismo multinacional. As práticas do governo federal continuaram centralizadoras, sem delegação de poder adicional às províncias. Segundo os autores, somente a identidade nacional canadense é reconhecida e as identidades regionais continuam ignoradas. Mantêmse assim intactas as relações de poder no federalismo canadense.

Como resultado de todo este processo histórico, em 1995, o governo quebequense promoveu um segundo referendo para o reconhecimento do Quebec como sociedade soberana, com poderes nacionais e autônomos em relação ao Canadá. O resultado do referendo (50,6\% contra versus 49,4\% a favor) não garantiu a soberania do Quebec, mas retratou claramente a tensão entre as relações Canadá - Quebec e o descontentamento da população do Quebec com o sistema federal. Este resultado imporia ao governo federal uma maior preocupação em promover a imagem de um federalismo atuante e justo, imagem reforçada pela realização de projetos em parceria com as províncias.

Por esse breve relato, constata-se que as relações entre as províncias e o governo federal canadense têm sido politicamente tensas ao longo da história do país. Esta tensão estende-se ao campo econômico, com a disputa entre as províncias por verbas públicas e investimentos privados (Pelletier, 2008). No entanto, nesse ambiente conflituoso, o governo canadense foi capaz de articular um projeto comum, que a priori teria grande visibilidade, mobilizando gestores provinciais e federais em uma comunidade de prática.

\section{A comunidade de prática e a sondagem canadense de satisfação de serviços públicos}

As sondagens de satisfação realizadas pelos governos centrais de diferentes países constituem um instrumento de gestão adotado a partir do fim dos anos de $1990^{(5)}$, por administrações públicas que mobilizaram esforços no sentido de promover uma reforma de gestão, caracterizada pela filosofia da Nova Gestão Pública (NGP) ${ }^{(6)}$. A NGP propõe a adoção de um novo modo de administrar, inspirado na gestão do setor privado, setor cujo nível de legitimidade era considerado como mais elevado do que o do setor público (Kirkpatrick \& Martinez-Lucio, 1995). Práticas como a divisão entre a planificação e a execução de políticas, a desregulamentação, a terceirização, a gestão por resultados, a descentralização, as parcerias intersetoriais, a filosofia cliente-fornecedor e o empowerment dos gestores constituem um conjunto, aliás, nem sempre coerente (Denhardt \& Denhardt, 2000), que supostamente deveria promover um governo que combatesse os déficits públicos e respondesse às exigências dos cidadãos.

No Canadá, desde 1998, é realizada uma sondagem de satisfação sobre os serviços oferecidos pelas três esferas de governo (federal, provincial e municipal), sondagem desenvolvida especialmente pelos governos canadenses. Além da satisfação dos entrevistados em relação aos serviços públicos, a sondagem também visa a identificar os principais fatores responsáveis por essa satisfação, bem como as normas de serviço consideradas ideais pelos respondentes e suas prioridades em termos de melhorias. As sondagens canadenses de satisfação foram realizadas em 1998, 2000, 2003, 2005 e 2008 e contaram com o respaldado dos governos provinciais e federal.

A ideia de promover a qualidade dos serviços públicos partiu, no governo federal canadense, do Bureau du Conseil Privé, órgão correspondente a uma Secretaria de Estado que presta assistência direta ao Primeiro Ministro e administra a função pública ${ }^{(7)}$. A melhoria da prestação dos serviços públicos constituía, juntamente com a gestão dos recursos humanos do governo federal e com o desenvolvimento da capacidade de elaboração de políticas públicas, as três prioridades de governo do Greffier du Conseil Privé $e^{(8)}$ no primeiro mandado do primeiro-ministro Jean Chrétien (1994 a 1999). 
Greffier delegou o mandato de se desenvolver uma estratégia para a melhoria dos serviços federais ao Centre canadien de gestion $(\mathrm{CCG})^{(9)}$, mais especificamente a um ex-colaborador ${ }^{(10)}$, precisando que seria desejável lançar uma iniciativa intergovernamental nesse sentido.

"Ela [Greffier du Conseil Privé] queria desenvolver o tema dos serviços e ela tinha em sua cabeça que era uma vantagem trabalhar com programas ministeriais que necessitam muita horizontalidade [colaboração entre ministérios] e verticalidade [colaboração entre governos] ${ }^{(11)}$... Então nós [do Centro canadense de gestão] decidimos que reuniríamos 40 pessoas que eram em sua maioria altos funcionários públicos e que eram campeões em serviços, mais alguns acadêmicos, americanos e canadenses, que faziam pesquisas nesta área" (entrevista com um membro do RSAC, tradução nossa).

Após o referendo quebequense de 1995, no qual praticamente metade da população do Quebec exprimiu seu desejo pela independência da província, a orientação do governo federal foi reforçar a ideia de unidade nacional, promovendo projetos de natureza federal-provincial. Em geral, tais iniciativas eram mal-acolhidas pelo governo do Quebec, que acusava o governo federal de manipular a opinião pública e criar uma falsa aparência de unidade canadense. No caso da melhoria dos serviços públicos, a realização de uma iniciativa intergovernamental justificava-se teoricamente. Isso porque o usuário público não sabe, necessariamente (nem se interessa em saber), qual esfera de governo lhe oferece um dado serviço, avaliando sua satisfação em relação aos serviços públicos como um todo.

O Centro Canadense de Gestão tomou a iniciativa de reunir um grupo de funcionários que trabalhavam com a questão dos serviços nos governos das províncias e no governo federal. $\mathrm{O}$ grupo denominado Réseau des services axés sur les citoyens (RSAC) ${ }^{(12)}$, em seguida, rebatizado Conseil de prestation des services du secteur public (CPSSP) ${ }^{(13)}$, chegou a mobilizar 220 pessoas e desenvolveu dez projetos para a melhoria da qualidade de prestação de serviços. Um deles (e o mais importante para a continuação do grupo) foi a sondagem nacional sobre a satisfação dos cidadãos em relação aos serviços públicos canadenses.

Este grupo apresentou um interesse particular para a pesquisa efetuada, pois acredita-se que sua existência tornou possível a realização de um projeto federal-provincial. Um dos líderes do grupo o definiu como sendo uma comunidade de prática $^{(14)}$, conceito que descreve o grupo com precisão e que caracteriza a estratégia de melhoria dos serviços desenvolvidos no Canadá.

Como apresentado no quadro teórico deste artigo, comunidades de prática são redes formadas por indivíduos que exercem funções e práticas similares em diferentes organizações. No caso canadense, indivíduos responsáveis pela qualidade de serviços nos vários governos (provinciais e federal) constituíram, em 1997, o Réseau des services axés sur les citoyens (RSAC). Em encontros coletivos (entre 1997 e 1998, foram realizados sete encontros) ou em comitês que se dedicavam a um tema em particular (como serviços eletrônicos, pontos únicos de serviço e sondagens de satisfação), gerentes e altos funcionários dos governos canadense e provinciais se reuniam para discutir suas abordagens e práticas de trabalho. Além de desenvolver projetos coletivos, a comunidade visava, sobretudo, ao compartilhamento de experiências e estratégias de promoção da qualidade dos serviços públicos.

As dimensões estrutural, relacional e cognitiva estão presentes, em várias proporções, no Réseau des services axés sur les citoyens (RSAC). De acordo com Lesser e Storck (2001), tais dimensões representam o valor específico das comunidades de prática. Como apresentado, a seguir, no caso estudado, elas não somente caracterizam a comunidade formada, mas também definem suas condições de existência.

A dimensão estrutural refere-se à habilidade dos indivíduos de estabelecerem contatos entre si. O sistema de governança canadense (denominado Whitehall) caracteriza-se pela presença de uma alta função pública de carreira, considerada apolítica. O percurso dos altos gestores no âmbito da administração federal, que são transferidos constantemente para novos cargos ${ }^{(15)}$, e a participação em grupos de trabalho e comitês contribuem para que os gestores públicos canadenses tenham um bom conhecimento da burocracia administrativa nas suas dimensões formal e informal. Ao longo de sua carreira, eles estabelecem contatos intra e intergovernamentais e identificam aqueles com quem 
estariam aptos a trabalhar num projeto comum. Acredita-se que tal contexto institucional contribuiu para o desenvolvimento da comunidade de prática.

A dimensão relacional diz respeito ao desenvolvimento de relações interpessoais entre os participantes da comunidade de prática. Segundo os entrevistados, o Réseau des services axés sur le citoyen sempre funcionou como um grupo informal, baseado na confiança e no compromisso mútuo. Quando o Réseau se formou, criou-se uma empatia entre os participantes devido ao fato de eles enfrentarem desafios similares nos seus governos, desafios para os quais as respostas não se encontravam nem em livros, nem em manuais, nem em experiências publicamente reconhecidas.

A importância dos contatos pessoais entre os membros das comunidades de prática é apontada por diversos autores (Fox, 2000; Lesser \& Storck, 2001; Wenger, 1999). É a partir dos contatos pessoais que as relações de confiança são construídas, apesar de as tecnologias da comunicação também constituírem pontos de apoio importantes para a coesão desses grupos (Persaud, Kumar, \& Kumar, 2001).

No caso do Réseau des services axés sur le citoyen (RSAC), todos os indivíduos entrevistados relataram uma ligação pessoal ou profissional que os estimulara a entrar no grupo: ou eles tinham trabalhado com alguém que já fazia parte do RSAC, ou tinham relações de amizade há muitos anos, ou tinham participado de um outro grupo interministerial ou intergovernamental com membros do Réseau.

Os acadêmicos convidados para participar do RSAC gravitavam igualmente em torno das instituições governamentais, pois já haviam participado de pesquisas junto ao Centro Canadense de Gestão ou ao Instituto de Administração Pública do Canadá. Eles apresentavam, assim, um olhar sobre a administração pública que era conhecido e considerado consonante com a orientação adotada pelo grupo. Até mesmo a firma de pesquisas Erin Research, que realizou as primeiras sondagens canadenses, foi apresentada ao grupo por um participante do RSAC, que já utilizara seus serviços em uma pesquisa promovida por seu governo provincial.

O Instituto de Administração Pública do Canadá (IAPC) ${ }^{(16)}$, que sempre se caracterizou por ser uma instituição fundada para e pelos os funcionários canadenses, parece ter tido um papel igualmente importante na constituição dessa rede de especialistas. Foi durante uma conferência anual do IAPC que foi lançada, pela primeira vez, a ideia de se criar um grupo sobre a questão dos serviços. $\mathrm{O}$ objetivo era estimular o debate e a troca de experiências entre funcionários de vários governos.

"Há uma unanimidade impressionante a respeito desta sondagem, desde o começo ... É notável.... Talvez
porque muitas destas pessoas se conheciam através do Instituto de Administração Pública do Canadá
[IAPC]. Por exemplo, eu conhecia .... do governo de Ontário, através do IAPC, há já 15 anos ... da divisão
de Serviços de Manitoba trabalhava para ... em Ontário e ele tinha me convidado para ir para Manitoba no
começo dos anos 1990 para .... da cidade de Vancouver, eu conhecia dos meus tempos na Colúmbia
Britânica, ... era meu 'PDG', ... eu conhecia do IAPC, onde estávamos trabalhando em ... então muitas
destas pessoas se conheciam ... muitas destas pessoas se conheciam e se apreciavam. E então este foi o
ingrediente mágico ... Estas pessoas todas tinham um compromisso com a melhoria dos serviços. Eram
campeões, não eram pessoas quaisquer ocupando cargos ... eles acreditavam nos serviços e na melhoria
dos serviços. E, em segundo lugar, a mágica era que muitos de nós nos conhecíamos e isso levou à uma
boa relação de trabalho. E em terceiro lugar, eu acho que todo mundo chegou às mesmas conclusões
sobre o que tinha que ser feito" (entrevista com um membro do RSAC, tradução nossa).

A importância dos contatos pessoais nas comunidades de prática justifica-se igualmente pela forma como o conhecimento é produzido e compartilhado em tais grupos, o que nos remete à dimensão cognitiva das comunidades de prática. Tal dimensão está intrinsecamente relacionada à transferência de conhecimentos tácitos, quando conhecimentos explícitos não se encontram disponíveis (Nonaka \& Takeuchi, 1995; Persaud et al., 2001). Na época, era o caso da promoção da qualidade dos serviços públicos adotada pelos governos centrais. Poucas publicações abordavam o assunto, inclusive porque as primeiras iniciativas do governo britânico foram divulgadas em 1998. 
As entrevistas sugerem que, no caso canadense, a formação da comunidade de prática se deu da forma relatada a seguir. Os contatos esporádicos dos indivíduos que trabalhavam com a qualidade dos serviços no âmbito de diversos governos, em grupos de trabalho ad hoc ou em eventos promovidos pelo IAPC, permitiram que esses indivíduos detectassem dissonâncias entre as práticas operadas pelo seu governo e as de outras administrações.

Quando a proposta de reunião em um grupo de trabalho sobre a melhoria dos serviços foi apresentada pela administração federal, o projeto foi considerado de interesse comum. Desde o primeiro encontro do grupo, em junho de 1997, em Ottawa, os participantes procuravam divulgar suas experiências e conhecer outras a fim de alargar o horizonte prático numa área, então, em evolução no setor público, em que nem as práticas de gestão, nem a produção acadêmica estavam bem ancoradas. É preciso salientar ainda que, segundo a própria percepção desses indivíduos, foi a problemática da melhoria dos serviços e os desafios que enfrentavam em seu quotidiano os fatores os quais deram origem ao Réseau des services axés sur le citoyen, e não o contrário. Foram criados comitês de trabalho no RSAC a fim de realizar diferentes projetos sobre a melhoria da qualidade de serviços públicos. A sondagem nacional sobre a satisfação com os serviços públicos foi um dos primeiros projetos levados a cabo pelo RSAC, indicando que a sondagem foi importante para reforçar a integração do grupo, bem como para a realização dos outros objetivos fixados pelos comitês.

“[No primeiro encontro do RSAC] ... basicamente nos colocamos três questões: 'Qual é o nosso
desempenho em serviços no setor público?'. Em segundo lugar: 'O que devemos saber para ter um
desempenho muito melhor do que o de agora?' .... E 'O que devemos fazer para ter um desempenho
muito melhor do que o de agora?'. E a resposta para a primeira questão era: 'Não sabemos qual é o nosso
desempenho, não há ninguém medindo isso. Não há praticamente nenhuma medida sendo feita.' E as
pessoas disseram: 'O que temos feito nos últimos 10 anos sobre os parâmetros de serviços e treinamento
para servir ao consumidor? Temos utilizado receitas prontas. E o que não temos feito é identificar nossa
performance no ponto de vista dos cidadãos, e o que eles acreditam que temos que fazer para melhorar.'
Esta era nossa resposta para a questão n. 1... Questão 2 ; 'O que devemos saber?' E a resposta era: o
quanto os canadenses estão satisfeitos com o serviço que oferecemos, temos que saber o que leva à
satisfação e temos que saber quais são as prioridades em termos de melhoria de serviços no setor público.
E então precisávamos fazer uma sondagem nacional, porque ninguém havia atacado este ponto, ninguém
havia jamais feito isso" (entrevista membro do RSAC, tradução nossa).

Nos termos de Nonaka e Takeuchi (1995), a sondagem representou, em si, a produção de conhecimento explícito e simbolizou a concretização dos esforços do grupo para a melhoria dos serviços. Assim, o RSAC conseguiu, desde o início, reforçar os "elos de confiança" entre os participantes. A importância da sondagem nos trabalhos do grupo é tal que não é por acaso que os membros do RSAC entrevistados frequentemente tomam emprestado o nome da iniciativa (Les citoyens d'abord, em português Os cidadãos em primeiro lugar para se referir à sondagem, que se chama na realidade Prononcez-vous - Manifeste-se).

"Houve um jantar à noite e foi quando nós tomamos conhecimento dos primeiros resultados preliminares da sondagem 'Os cidadãos em primeiro lugar...' apresentou seu primeiro rascunho da ferramenta de medidas comuns. Então ambos os apresentaram naquela noite, e foi uma noite bastante importante, porque lá estavam dois documentos que certamente teriam um impacto direto no trabalho que eu estava fazendo, e respondia em muito às necessidades das pessoas que estavam naquela sala" (entrevista membro do RSAC, tradução nossa).

A articulação da comunidade de prática canadense (RSAC) tornou possível a união de membros de vários governos para a realização do projeto de sondagem em nível nacional. No entanto, não era esperado que a colaboração das províncias com o governo federal se concretizasse sem dificuldades, dada a própria história do governo federal canadense e os movimentos separatistas existentes. 


\section{Uma Análise Crítica sobre a Atuação da Comunidade de Prática na Viabilização da Sondagem Canadense}

A pesquisa evidenciou que a singularidade da estratégia canadense para a implementação de sondagens de satisfação em relação aos serviços públicos se encontra na formação de uma rede, o Réseau des Services Axés sur le Citoyen ${ }^{(17)}$. Na rede de funcionários canadenses formada, está presente a maior parte dos elementos que caracterizam uma comunidade de prática, como descrito teoricamente (Lesser \& Stock, 2001; Wenger, 1999, 2000). Os participantes do RSAC se conheciam previamente e desenvolviam suas atividades de trabalho em um campo preciso, qual seja, a melhoria da qualidade dos serviços. Eles reuniram-se enquanto indivíduos que apresentavam o interesse comum de aprimorar suas práticas e conhecimentos sobre a questão dos serviços. O próprio grupo definiu sua estrutura e seu modo de funcionamento em comitês articulados em torno de projetos.

A comunidade de prática foi mobilizada pelo governo federal canadense. Segundo os entrevistados, a liderança do projeto foi definida pelo critério do conhecimento (o que é essencial para a legitimação das lideranças em comunidades de prática, segundo Lesser e Stock, 2001): um funcionário do governo federal, membro do Centro Canadense de Gestão e especialista no assunto da qualidade de serviços ${ }^{(18)}$, assumiu o papel de planejador, mobilizador e gestor do projeto. O papel do membro do governo federal na rede sugere a ascendência do governo federal sobre o RSAC, ideia, no entanto, refutada por todos os entrevistados. A liderança do governo federal foi negada veementemente (mesmo que o governo federal tenha financiado $75 \%$ dos custos da primeira sondagem realizada). "Bom, eu acho que a rede foi incubada pelo governo federal, mas ela representava gente de todos os outros governos, e isso através do país..." (entrevista membro do RSAC, tradução nossa).

Como visto, havia um interesse instrumental de desenvolver a qualidade de serviços públicos e, para concretizar ações nesse sentido, o governo federal recorreu à formação de uma comunidade de prática, que teoricamente se fundamenta pela promoção do aprendizado sobre práticas de trabalho precisas. No entanto, o governo federal também tinha outros interesses em jogo, de caráter valorativo e ideológico, que se exprimiam em duas dimensões: a promoção da filosofia dos serviços e a promoção do federalismo canadense.

Quanto à primeira dimensão, desde a força tarefa Fonction Publique 2000, instituída em 1989, a qualidade dos serviços se destacou como elemento mobilizador e definidor dos esforços de reforma na gestão pública canadense. Em face a questões muito mais polêmicas, como as privatizações e a importante redução de efetivos da função pública, que fizeram parte da reforma administrativa, a promoção da qualidade dos serviços apresentou-se como elemento unificador das diversas visões de reforma, uma vez que é inquestionável a vocação da administração pública de servir ao cidadão. Orientada pela ideia de oferecer melhores serviços aos cidadãos, foi implantada, no Canadá, uma reforma administrativa considerada, por diversos autores (como Pollitt \& Bouckaert, 2000), como hesitante e cautelosa, desenvolvida a um ritmo mais lento comparativamente às reformas administrativas da Inglaterra e dos Estados Unidos, por exemplo ${ }^{(19)}$.

Essa reforma veiculava a postura ética desenvolvida pelos altos funcionários do governo canadense e resumida no Rapport Tait ${ }^{(20)}$, de 1996. O documento apresenta a reforma de gestão como caracterizada pelo desejo de conciliação entre valores profissionais tradicionais da função pública canadense (como a competência profissional, o mérito, a objetividade e a imparcialidade) e valores profissionais emergentes, ligados às reformas administrativas (como a qualidade, a inovação, a iniciativa, o foco sobre o cliente e as parcerias). Dessa forma, os altos funcionários canadenses buscaram preservar, em vista das mudanças que se impunham ao serviço público (e que, inspiradas da gestão privada, visavam à eficiência, à eficácia e à economia), valores que lhes eram caros. O impacto da reforma ${ }^{(21)}$ foi diluído no discurso de melhoria dos serviços aos cidadãos canadenses. Nessa teia, a comunidade de prática canadense foi um veículo promotor da ideia de melhoria dos serviços, segundo concebida pelos altos funcionários canadenses. Sendo que a rede em questão balizou as ações de 
melhoria dos serviços no Canadá através de um discurso ambíguo (incorporando ao discurso mercantilista da reforma e das sondagens de satisfação conceitos como cidadania e interesse público).

Secundariamente, havia também o interesse do governo federal de promover o federalismo, interesse reanimado pelos resultados do segundo referendo quebequense, que quase legitimaram a soberania do Quebec em relação ao Canadá, contestando o sistema federal vigente. No entanto o ambiente para a promoção do federalismo era, no mínimo, hostil, sobretudo, pela oposição quebequense, coordenada pelo Parti Québécois, então, no governo do Quebec, e pelo Bloc Québécois, partido, na época, atuante no governo federal. Além disso, outras províncias contestavam o caráter distinto da sociedade quebequense e exigiam reconhecimento similar pelo governo federal. Assim, não só promover o federalismo era uma tarefa difícil, mas promover qualquer iniciativa com a colaboração das províncias tornava-se uma ação em terreno minado.

A pesquisa realizada evidencia que a articulação da comunidade de prática canadense serviu para diminuir (ou mesmo esvaziar) o conteúdo político e ideológico do projeto de sondagens, concentrando a atenção dos participantes no conteúdo técnico das comunidades de prática, que se fundamenta nos processos de aprendizagem (comunhão de informações e práticas, e transformação de conhecimentos tácitos em explícitos). Assim, através da comunidade de prática, a iniciativa canadense privilegiou a racionalidade instrumental, o que possibilitou a realização de um projeto conjunto. Porém a realização de tal projeto concretizou também, simultaneamente, a efetivação de racionalidades calcadas em valores e ideologias de governo, próprias ao governo federal do Canadá e à reforma de gestão em curso.

É interessante ressaltar que, durante a pesquisa, todos os entrevistados reafirmaram a função de aprendizagem da comunidade de prática, os interesses comuns e o comportamento consensual do grupo. Todos os entrevistados declararam que a sua participação no Réseau des Services Axés sur le Citoyen era voluntária e assinalaram as virtudes de atuação de um grupo informal e autônomo. Tais relatos sugerem que os participantes acreditaram na instituição da comunidade de prática, legitimando sua existência pela possibilidade de aprendizagem. Enquanto o caráter técnico e racional instrumental (cognitivo) da comunidade foi ressaltado, seu caráter político ou ideológico (presente em qualquer tipo de iniciativa) foi omitido por todos os entrevistados. A fala de um dos entrevistados, quando perguntado se o RSAC havia sofrido críticas dos governos provinciais, resume a posição do grupo.

\footnotetext{
"De jeito nenhum. Porque tínhamos representantes de todas as províncias. Por exemplo, quando fizemos o primeiro encontro regional em Ontário, eu sugeri ao governo do Québec que mandasse alguém para conhecer o que estávamos fazendo, porque eles tinham tomado parte da rede inicial, eles estavam entre os 44, e eu disse: 'Queremos organizar algo em Montreal, então mande alguém para Toronto para ver como o evento foi organizado por Ontário, pelo município [Toronto] e pelos funcionários federais em região'. E eles fizeram isto, e eles se engajaram ativamente, e o cara voltou dizendo para seus colegas: 'Nós temos que fazer isso, é muito bom. Nós temos que ajudar a organizar o evento em Montreal'. Então tivemos um excelente evento em Montreal em maio, mesmo se as relações entre os governos não são muito boas, as relações entre os funcionários são boas. E eu me lembro, no encontro regional em Montreal, eu me lembro dos caras da província e de Montreal dizendo em seu discurso de abertura: ' Há um cidadão. Há três níveis de governo, mas há somente um cidadão. E nós temos que descobrir como servir, trabalhar conjuntamente para este cidadão"” (membro do RSAC, tradução nossa).
}

Um segundo fator possibilitou o sucesso da sondagem canadense, fator que, de certa forma, corrobora o esvaziamento da lógica política da iniciativa das sondagens pela instituição da comunidade de prática. Trata-se do distanciamento do projeto de melhoria dos serviços da esfera política dos governos.

Alguns entrevistados ressaltaram que a qualidade dos resultados atingidos pelo RSAC devia-se, principalmente, ao fato de que esse grupo era formado por funcionários e se situava à margem das estruturas políticas intergovernamentais. O fato de não pertencer à estrutura formal da administração pública deu ao grupo maior liberdade de ação e permitiu evitar que a esfera política federal exercesse uma intervenção formal nas orientações do RSAC. O distanciamento de outras esferas políticas também foi ressaltado pelos entrevistados, que afirmaram o desinteresse ou mesmo o 
desconhecimento da iniciativa pelos Parlamentos ou por organizações da sociedade civil, que nunca participaram nem opinaram a respeito do projeto de sondagens.

\footnotetext{
"Eu sempre disse que uma das razões que eu acho que nós fomos capazes de ir tão longe e fazer tanta coisa é porque nós não estávamos trabalhando dentro de uma estrutura formal. Não dizia respeito às relações federais provinciais, porque para trabalhar dentro deste quadro... há regras demais sobre como trabalhar juntos enquanto províncias e governo federal. Não era sobre ... nosso perfil, era sobre como desenvolver a agenda de serviços, como dividir informações entre nós..." (entrevista membro do RSAC, tradução nossa).
}

Segundo gestores entrevistados, a escolha de organizações consideradas como bases neutras para atuarem como responsáveis pelo projeto Les citoyens d'abord contribuiu também para que o grupo concebesse os projetos do RSAC como iniciativas técnicas de colaboração intergovernamental. As organizações que sediaram o projeto foram as seguintes, em ordem cronológica: Centre canadien de gestion, Institut d'Administration publique du Canada e Institut des services axés sur le citoyen (criado a partir de recomendações do RSAC). Somente o primeiro órgão pertencia à administração direta do governo canadense. Mesmo assim, o Centre canadien de gestion, órgão de pesquisa, formação e desenvolvimento dos gestores federais, era portador de certa legitimação científica, calcada na suposta objetividade positivista. Muito provavelmente, se o Conseil du Trésor ${ }^{(22)}$ do Canadá ou o Bureau du Conseil Privé - que são instituições do governo federal de caráter eminentemente político - tivessem assumido a responsabilidade pela realização das sondagens canadenses, os representantes das províncias teriam apresentado maior resistência.

Finalmente, a participação do Quebec na sondagem também pode ser compreendida a partir do distanciamento dos responsáveis pela sondagem nessa província da esfera política. Diferentemente de outras províncias, no governo do Quebec, os indivíduos responsáveis pela sondagem se situavam no Ministério da Imigração e Relações com os Cidadãos, estando, dessa maneira, mais afastados das agências centrais do governo e dispondo de menor visibilidade política. Durante a entrevista, o representante do Québec no RSAC fez questão de ressaltar que o governo quebequense visava à adoção de um instrumento de pesquisa de satisfação especialmente concebido em adequação à realidade da província, sem, contudo reconhecer o caráter político da sondagem canadense. O entrevistado referia-se à sondagem do RSAC como um projeto de pouca importância, sugerido pelo grupo do (representante do governo federal), ao qual a província havia aderido, em colaboração a outros gestores públicos interessados em promover a qualidade de serviços.

$\mathrm{Na}$ mesma linha de argumentação, não é de se estranhar a pequena visibilidade pública conferida à sondagem, que, em todos esses anos, nunca foi objeto de uma campanha de propaganda do governo (embora os dados sejam extremamente favoráveis à qualidade dos serviços públicos canadenses). Os entrevistados atribuíram o fato ao parco interesse da imprensa sensacionalista por projetos governamentais bem-sucedidos e definiram a sondagem como um negócio interno ao governo, que interessava, principalmente, aos funcionários públicos, que buscam uma maior "eficácia" em suas ações. Todavia, se a estratégia, consciente ou não conscientemente empregada, era distanciar a iniciativa da esfera política, a pouca visibilidade pública lhe favoreceu, não despertando o interesse do público nem dos políticos sobre os resultados da sondagem ou quanto à maneira como esta tem sido realizada todos esses anos.

\section{Conclusão}

Neste artigo é apresentada a experiência canadense de implementação de sondagens nacionais de satisfação em relação aos serviços públicos oferecidos pelos municípios, províncias e governo federal. Acredita-se que essa experiência possa ser inspiradora ao setor privado, pois, através de uma comunidade de prática, foi viabilizado um projeto comum, que contou com a colaboração dos parceiros na rede formada, mesmo que esses parceiros estivessem situados em um ambiente caracterizado pela rivalidade e pela contestação do federalismo. 
Pode-se, aqui, argumentar, como fruto de uma interpretação crítica do fenômeno, que a comunidade de prática, legitimada, por seus participantes, como uma forma de organização para a aprendizagem, esvaziou (ou diminuiu) a iniciativa de sondagens de sua racionalidade política e ideológica. Ao mesmo tempo, esse tipo de articulação, entre seus atores, possibilitou o afastamento do projeto da esfera política dos governos através da qual o projeto provavelmente não se realizaria.

Como todo o estudo, a pesquisa realizada apresenta limites. Primeiramente, trata-se do estudo de um contexto de governança pública particular, dificilmente reproduzido em outras administrações públicas. Em segundo lugar, foram entrevistados apenas indivíduos bastante implicados no projeto da sondagem nacional, identificados por uma técnica de bola de neve. Correu-se, assim, o risco de eliminar informantes, sobretudo, a respeito da formação e do funcionamento da rede canadense.

Parte destes limites é, contudo, sancionada pela postura epistemológica adotada, construtivista e crítica, segundo a qual, a contextualização dos problemas e a postura ideológica dos sujeitos são elementos fundamentais da pesquisa. Por isso mesmo, procurou-se abordar indivíduos representantes de governos em conflito e que, em teoria, apresentariam pontos de vista diferentes atinentes à realização da sondagem (o que, no entanto, não ocorreu).

O terceiro limite que pode ser apontado diz respeito à possibilidade de transferência dos resultados para situações vividas por empresas privadas. No entanto, sempre em consonância com uma perspectiva crítica, não se trata aqui de oferecer ao setor privado uma receita ou fórmula de sucesso, recomendando que as comunidades de prática sejam criadas como estratégia de realização de projetos comuns em ambientes competitivos e turbulentos. Nem se coloca que as comunidades de prática sejam estruturas de colaboração capazes de ludibriar seus participantes, concentrando sua atenção no aspecto técnico e racional instrumental dos projetos.

Acredita-se simplesmente que essa experiência, oriunda do setor público canadense, possa acrescentar ao setor privado, no sentido de despertá-lo à possibilidade de aproveitar-se de contatos já estabelecidos (como os que existiam entre os gestores canadenses) para a formação de redes, objetivando o desenvolvimento de projetos conjuntos. Trata-se de desenvolver uma segunda compreensão das potencialidades destas redes que, além de se apresentarem como um veículo de aprendizagem, são, também, um veículo de propagação de ideologias. Além disso, o caso descrito busca alertar os participantes de tais comunidades que, embora concentrem a atenção dos indivíduos sobre a aprendizagem e a racionalidade instrumental, há sempre outras lógicas presentes em sua constituição, que são veiculadas, construídas e desconstruídas durante o desenvolvimento do projeto comum.

Uma das áreas da empresa privada carente de realização de projetos em colaboração interorganizacional ou mesmo interdepartamental é o setor de pesquisa e desenvolvimento. Outros setores específicos de tecnologia ou gestão também enfrentam o mesmo desafio. E, no entanto, esses setores, geralmente, são compostos por indivíduos que, dependendo do seu grau de especialização, pertencem a associações profissionais ou de pesquisa nas quais estabelecem contatos que viabilizariam a formação de comunidades de prática para o desenvolvimento de um projeto preciso, chancelado pelas organizações envolvidas. Assim, reforçar-se-ia a lógica do aprendizado e do desenvolvimento técnico em colaboração, mesmo em um ambiente hostil, caracterizado pela competição inter ou intraorganizacional. Experiências como a da IBM, que implantou mundialmente um projeto de desenvolvimento de comunidades de prática (Gongla \& Rizzuto, 2001), e as comunidades de prática em P\&D de multinacionais (Hong \& O, 2009; Persaud et al., 2001) ilustram a adequação das comunidades em setores voltados ao desenvolvimento de tecnologia de ponta.

Se a Nova Gestão Pública apresenta, como filosofia, a transferência ou a adaptação de práticas desenvolvidas no setor privado para o setor público em busca de maior eficiência, eficácia e economia, é sugerido, através do estudo apresentado neste artigo, que seja considerada a lógica inversa, onde uma experiência desenvolvida no setor público tem a ensinar ao setor privado quanto à articulação de indivíduos em redes e ao sucesso de projetos comuns em ambientes turbulentos. 


\section{Artigo recebido em 23.04.2012. Aprovado em 17.10.2012.}

\section{Notas}

${ }^{1}$ A teoria das comunidades de prática (Communities of practice theory [COP]) adota uma perspectiva construtivista no campo da aprendizagem organizacional. Ela retoma a ideia de situated learning, segundo a qual, a aprendizagem ocorre, em boa parte, por fora das escolas formais. Neste caso, ela ocorreria no campo, na prática de trabalho.

${ }^{2}$ Em 1995, por exemplo, a IBM implantou em nível mundial um projeto de desenvolvimento de comunidades de prática, analisado por Gongla e Rizzuto (2001).

${ }^{3}$ Persaud et al. (2001) empreenderam uma pesquisa sobre comunidades de prática cujos participantes trabalhavam em laboratórios de desenvolvimento e pesquisa de 45 multinacionais de origem canadense, americana, japonesa e europeia (manufaturas de artigos eletrônicos e elétricos, indústrias farmacêuticas e químicas e indústria automobilística).

${ }^{4}$ Falantes de língua francesa e inglesa, respectivamente.

${ }^{5}$ Em 1998, o governo central da Inglaterra foi o primeiro a realizar uma sondagem desse tipo: Services First.

${ }^{6}$ Para uma excelente revisão da reforma administrativa no Brasil, ver Abrúcio, F. L. (2007). Trajetória recente da gestão pública brasileira: um balanço crítico e a renovação da agenda de reformas [Edição Especial]. Revista de Administração Pública, 41, 67-86. doi: 10.1590/S0034-76122007000700005.

${ }^{7}$ O Bureau du Conseil Privé é uma das agências centrais do governo do Canadá de maior peso, sobretudo, em termos da definição de estratégias de gestão da administração canadense.

${ }^{8}$ Alto funcionário de carreira, dirigente do Conseil Privé.

${ }^{9}$ Centro Canadense de Gestão. Este órgão, juntamente com a Formation et perfectionnement Canada et Formation linguistique Canada, constituiu, em 2004, a École de la fonction publique du Canada, que presentemente faz parte do portfólio de organizações do Conseil Privé.

${ }^{10}$ Este indivíduo era diretor de pesquisa do Centro Canadense de Gestão e havia trabalhado anteriormente no Bureau $d u$ Conseil Privé.

${ }^{11} \mathrm{O}$ entrevistado mesmo definiu os termos horizontalidade e verticalidade.

${ }^{12}$ Rede de serviços voltada para os cidadãos.

${ }^{13}$ Conselho de prestação de serviços do setor público. Para facilitar a compreensão do leitor, ao longo deste texto, o RSAC / CPSSP (grupo responsável pela sondagem canadense) será denominado simplesmente RSAC.

${ }^{14}$ Comunidade de prática, do inglês community of practice. No entanto, o membro do governo canadense entrevistado tinha traduzido o termo inglês como communauté d'expertise, termo que ele utilizou para caracterizar o RSAC.

${ }^{15}$ Orientação seguida após as recomendações da Comissão Glassco (1962), que exortava à formação de altos funcionários com um perfil mais gerencialista e generalista, e menos especializados no setor de políticas de um ministério ou de uma agência.

${ }^{16}$ O Instituto de Administração Pública do Canadá é uma instituição fundada em 1947, que se dedica à formação de funcionários públicos e ao desenvolvimento de pesquisas sobre a administração pública. No Canadá, a principal revista científica em administração pública é publicada pelo IAPC, assim como livros e relatórios de pesquisa. Anualmente, o IAPC promove uma série de conferências, com destaque para o congresso anual que reúne funcionários, consultores e acadêmicos da área.

${ }^{17}$ Como mencionado, a pesquisa que deu origem aos resultados apresentados neste artigo compreendia um estudo comparativo entre as estratégias desenvolvidas pelos governos centrais dos Estados Unidos e do Canadá para a implantação de sondagens de satisfação (Gazzoli, 2004a). Esta pesquisa, além de estudos que incluíram a realização de sondagens de satisfação na Inglaterra e no Brasil (Gazzoli, P. (2004b). Como anda sua satisfação a respeito dos serviços públicos? as pesquisas de satisfação na Inglaterra, no Canadá, nos Estados Unidos e no Brasil. Revista de Administração FEAD, 1(1), 129144), reconheceu a singularidade da estratégia canadense.

${ }^{18}$ Este gestor tinha a experiência de implantação de um programa de melhoria de serviços na Colúmbia Britânica, no início dos anos de 1990.

${ }^{19}$ Rouillard, C. (2001). Sur la reconduction de la continuité à travers la rupture: une analyse critique de La Releve. In M. Charih \& P. P. Tremblay (Eds.), Enjeux de l'administration publique (pp. 215-238). Quebec: École nationale d'administration publique. é mais contundente, classificando a reforma de gestão canadense como ambígua e fonte de confusão para os funcionários do governo. 


\footnotetext{
${ }^{20} \mathrm{O}$ relatório produzido por John Tait, alto funcionário do governo canadense, intitulava-se De solides assises. Rapport sur le groupe de travail sur les valeurs et l'éthique dans la fonction publique (Bases sólidas. Relatório sobre o grupo de trabalho sobre os valores e a ética na função pública), mas ficou conhecido como Rapport Tait.

${ }^{21}$ Cujos efeitos negativos se fizeram sentir concretamente pela função pública, com a redução, entre 1994 e 1998, de 55.000 postos de trabalho.

${ }^{22}$ Órgão que exerce algumas funções equivalentes às do Ministério da Fazenda, responsável pelo orçamento do governo federal canadense.
}

\section{Referências}

Alvesson, M., Bridgman, T., \& Willmott, H. (Eds.) (2009). The oxford handbook of critical management studies (Introduction). New York: Oxford University Press.

Alvesson, M., \& Deetz, S. (2000). Doing critical management research. Thousand Oaks, CA: Sage.

Alvesson, M., \& Willmott, H. (1996). Making sense of management: a critical introduction. Thousand Oaks, CA: Sage.

Brandon, T., \& Charlton, J. (2011). The lessons learned from developing an inclusive learning and teaching community of practice. International Journal of Inclusive Education, 15(1), 165-178. doi: $10.1080 / 13603116.2010 .496214$

Broschek, J. (2010). Federalism and political change: Canada and Germany in historicalinstitutionalist perspective. Canadian Journal of Political Science, 43(1), 1-24. doi: $10.1017 / \mathrm{S} 0008423909990023$

Denhardt, R. B., \& Denhardt, J. V. (2000). The new public service: serving rather than steering. Public Administration Review, 60(6), 549-559. doi: 10.1111/0033-3352.00117

Espinosa, M. D. M. B, \& Suanes, A. M. (2011). Corporate entrepreneurship through joint venture. International Entrepreneurship and Management Journal, 7(3), 413-430. doi: 10.1007/s11365011-0203-2

Fox, S. (2000). Communities of practice, foucault and actor-network theory. Journal of Mangement Studies, 37(6), 853-868.

Gagnon, A.-G. (2001). The moral foundations of assymetrical federalism: a normative exploration of the case of Quebec and Canada. In A.-G. Gagnon \& J. Tully (Eds.), Multinational democracies (pp. 319-337). Cambridge: Cambridge University Press.

Gagnon, A.-G. (2008). La raison du plus fort - Plaidoyer pour le fédéralisme multinational. Québec: Éditions Québec/Amérique.

Gazzoli, P. (2004a). Les sondages sur la qualité des services au Canada et aux États-Unis: des prétentions discursives universelles aux particularismes des choix stratégiques et opérationnels (Thèse doctorat). École Nationale d'Administration Publique, Montréal, Quebec, Canadá.

Gongla, P., \& Rizzuto, C. R. (2001). Evolving communities of practice: IBM global services experience. IBM Systems Journal, 40(4), 842-862. doi: 10.1147/sj.404.0842

Guba, E., \& Lincoln, Y. S. (1994). Competing paradigms in qualitative research. In N. K. Denzin (Ed.), Handbook of qualitative research (pp. 105-117). Thousand Oaks, CA: Sage. 
Habhab-Rave, S. (2010). The role of the communities of practice in the process of knowledge management in innovative enterprises: a case study through intersite comparison. Revue des sciences de gestion, 45(241), 43-54.

Heizmann, H. (2011). Knowledge sharing in a dispersed network of HR practice: zooming on power/knowledge struggles. Management Learning, 42(4), 379-393. doi: $10.1177 / 1350507610394409$

Holstein, J. A., \& Gubrium, J. F. (2011). The constructionist analytics of interpretive practice. In N. K. Denzin \& Y. S. Lincoln (Eds.), The SAGE handbook of qualitative research (pp. 341-358). Thousand Oaks, CA: SAGE.

Hong, J. F. L., \& O, F. K. H. (2009). Conflicting identities and power between communities of practice: the case of IT outsourcing. Management Learning, 40(3), 311-326. doi: $10.1177 / 1350507609104342$

Hughes, J., Jewson, N., \& Unwin, L. (2007). Communities of practice: critical perspectives. Abingdon: Routledge.

Kerneghan, K. (1982). Intergovernmental administrative relations in Canada. In K. Kerneghan (Ed.), Public administration in Canada: selected readings (pp. 80-93). Toronto: Methuen.

Kirkpatrick, I., \& Martinez-Lucio, M. (1995). The politics of quality in the public sector [Introduction]. London: Routledge.

Klijn, E., Reuer, J. J., Buckley, P. J., \& Glaister, K. W. (2010). Combinations of partners' joint venture formation motives. European Business Review, 22(6), 576-590. doi: $10.1108 / 09555341011082899$

Lesser, E. L., \& Storck, J. (2001). Communities of practice and organizational performance. IBM Systems Journal; Armonk, 40(4), 831-841. doi: 10.1147/sj.404.0831

Mazière, F. (2010). L'analyse du discours: histoire et pratiques. Paris: Presses Universitaires de France.

Meagher-Stewart, D., Solberg, S. M., Warner, G, Macdonald J. A., McPherson, C., \& Seaman, P. (2012). Understanding the role of communities of practice in evidence-informed decision making in public health. Quality Health Research, 29, 1-17. doi: 10.1177/1049732312438967

Mutch, A. (2003). Communities of practice and habitus: a critique. Organization Studies, 24(3), 383401.

Noël, A. (1998). Le principe fédéral, la solidarité et le partenariat. In G. Laforest \& R. Gibbins (Ed.), Sortir de l'impasse. Les voies de la réconciliation (pp. 263-295). Montréal: Institut de Recherche en Politiques Publiques.

Nonaka, I., \& Takeuchi, H. (1995). The knowledge creation company: how Japanese companies create the dynamics of innovation. Oxford: Oxford University Press.

Packer, M. J. (2011). The science of qualitative research. New York: Cambridge University Press.

Pelletier, R. (2008). Le Québec et le fédéralisme canadien: un regard critique. Québec: Les Presses de l'Université Laval. 
Peräkyla, A., \& Ruusuvuori, J. (2011). Analysing talk and text. In N. K. Denzin \& Y. S. Lincoln (Eds.), The SAGE handbook of qualitative research (pp. 529-544). Thousand Oaks, CA: SAGE.

Persaud, A., Kumar, U., \& Kumar, V. (2001). Harnessing scientific and technological knowledge for the rapid development of global innovations. Engineering Management Journal, 13(1), 12-19.

Pollitt, C., \& Bouckaert, G. (2000). Public management reform: a comparative analysis. Oxford: Oxford University Press.

Radin, B. A., \& Boase, J. P. (2000). Federalism, political structure and public policy in the united states and Canada. Journal of Comparative Policy Analysis, 2(1), 65-89. doi: 10.1023/A:1010050314516

Raelin, J. A. (1998). Work-based learning in practice. Journal of Workplace Learning, 10(6/7), 280283. doi: $10.1108 / 13665629810236183$

Rocher, F., Rouillard, C., \& Lecours, A. (2001). Recognition claims, partisan politics and institutional constraints: Belgium, Spain and Canada in a comparative perspective. In A-G. Gagnon \& J. Tully (Eds.), Multinational democracies (pp. 176-200). Cambridge, UK: Cambridge University Press.

Rouillard, C. (1999). Le syndrome du survivant et la fonction publique fédérale du Canada : une étude théorique à la lumière de la théorie critique et de la déconstruction derridéenne (Thèse doctorat). Departamento de Ciência Política, Carleton University, Canadá.

Rouleau, L. (2007). Théories des organisations approches classiques, contemporaines et de l'avantgarde. In L. Rouleau, Les théories critiques (Cap. 10, pp. 179-197). Québec: Presses de l'Université du Québec.

Sabourin, P. (2009). L'analyse de contenu. In B. Gauthier \& J-P. Beaud (Eds.), Recherche sociale: de la problématique à la collecte des données (pp. 415-444). Québec: Presses de l'Université du Québec.

Scherer, A. G. (2009). Critical theory and its constribution to critical management studies. In M. Alvesson, T. Bridgman, \& H. Willmot (Eds.), The oxford handbook of critical management studies (Cap. 2, pp. 29-51). New York: Oxford University Press.

Silverman, D., \& Marvasti, A. B. (2008). Doing qualitative research: a comprehensive guide. Los Angeles: SAGE Publications.

Simon, H. (1947). Administrative Behavior: a study of decision making processes in administrative organization. New York, NY: The Free Press.

Simpson, D. (2011). Reform, inequalities of process and the transformative potential of communities of practice in the pre-school sector of England. British Journal of Sociology of Education, 32(5), 699-716. doi: 10.1080/01425692.2011.596366

Snyder, W., Wenger, E., \& Briggs, X. S. (2004). Communities of practice in government: leveraging knowledge for performance. The Public Manager, 32(4), 17-21.

Souza-Silva, J. C. (2009). Conditions and challenges for the rise of communities of practice in organizations. Revista de Administração de Empresas, 49(2), 176-189. doi: 10.1590/S003475902009000200005

Tait, J. (1996). De solides assises: Rapport du groupe de travail sur les valeurs et l'éthique dans la fonction publique. Ottawa: Centre canadien de gestion. 
Tong, T. W., \& Reuer, J. J. (2010). Competitive consequences of interfirm collaboration: how joint ventures shape industry profitability. Journal of International Business Studies, 41(6), 10561073. doi: $10.1057 /$ jibs. 2010.2

Vickers, D., \& Fox, S. (2010). Towards practice-based studies of HRM: an actor-network and communities of practice informed approach. International Journal of Human Resource Management, 21(6), 899-914. doi: 10.1080/09585191003729366

Wenger, E. (1999). Communities of practice: learning, meaning and identity. Cambridge: Cambridge University Press.

Wenger, E. (2000). Communities of practice and social learning systems. Organization, 7(2), 225-246. doi: $10.1177 / 135050840072002$

Yen-Tsung, H. (2010). Learning from cooperative inter-organizational relationships: the case of international joint venture. The Journal of Business \& Industrial Marketing, 25(6), 454-467. 